Muris, P., Meesters, C., Morren, M., Moorman, L.

Anger and hostility in adolescents: relationships with self-reported attachment

style and perceived parental rearing styles.

Journal of Psychosomatic Research: 57, 2004, nr. 3, p. 257-265

\begin{tabular}{|l|l|}
\hline Postprint Version & 1.0 \\
\hline Journal website & $\underline{\mathrm{http}: / / \text { www.sciencedirect.com/science/journal/00223999 }}$ \\
\hline Pubmed link & $\underline{\underline{\mathrm{http}} / / \text { www.ncbi.nlm.nih.gov/entrez/query.fcgi?cmd=Retrieve\&db=pubmed\&dop }}$ \\
\hline DOI $=$ Abstract\&list_uids=15507252\&query_hl=34\&itool=pubmed_docsum
\end{tabular}

* Corresponding author. Tel.: +31-43-38811601; fax: +31-43-3615735.

E-mail address: p.muris@dep.unimaas.nl (P. Muris).

\title{
Anger and hostility in adolescents: Relationships with self-reported attachment style and perceived parental rearing styles
}

\author{
Peter Muris*, Cor Meesters, Mattijn Morren, Lidwine MoOrman \\ Department of Medical, Clinical, and Experimental Psychology, P.O. Box 616, 6200 MD Maastricht, \\ The Netherlands
}

\begin{abstract}
Objective: To examine relationships between self-reported attachment style and parental rearing behaviors, on the one hand, and anger/hostility, on the other hand, in a sample of nonclinical adolescents $(N=441)$. Method: Participants completed (a) a single-item measure of attachment style; (b) a questionnaire measuring perceptions of parental rearing behaviors; and (c) two scales assessing anger and hostility. Results: Self-reported attachment style was related to anger/hostility. That is, adolescents who defined themselves as avoidantly or ambivalently attached displayed higher levels of anger/hostility than adolescents who classified themselves as securely attached. Furthermore, perceived parental rearing was also related to anger/hostility. More specifically, low levels of emotional warmth and high levels of rejection, control, and inconsistency were accompanied by high levels of anger/hostility. Finally, regression analyses showed that both attachment status and parental rearing behaviors accounted for a unique and significant proportion of the variance in anger/ hostility. Conclusion: These findings are in keeping with the notion that family environment factors such as attachment style and parental rearing are involved in the development of anger/ hostility in youths.
\end{abstract}

\section{INTRODUCTION}

A wealth of studies in health psychology and behavioral medicine have indicated that a constellation of anger and hostility can be considered as a significant psychological risk factor for the development of coronary heart disease [1]. In general, hostility can be defined as an attitudinal set that motivates aggressive behavior directed toward the destruction of objects or injury of people, whereas anger is used to refer to an affective experience, ranging from mild irritation or annoyance to full-blown rage [2]. The scientific interest in the link between anger/hostility and CHD originated from research on the Type A Behavior Pattern, which is characterized by a chronic sense of time urgency, impatience, competitiveness, anger, hostility, and a high need to show competency and to maintain control. While prospective epidemiological studies have demonstrated that the Type A Behavior Pattern is a significant risk factor for developing CHD in initially healthy populations $[3,4]$, subsequent analyses examining individual elements of this multifaceted behavior pattern have shown that anger/hostility should be viewed as the toxic component $[5,6]$. 
Muris, P., Meesters, C., Morren, M., Moorman, L.

Anger and hostility in adolescents: relationships with self-reported attachment

style and perceived parental rearing styles.

Journal of Psychosomatic Research: 57, 2004, nr. 3, p. 257-265

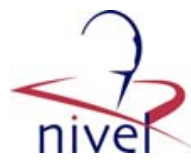

Although serious CHD is rarely observed in children, there is evidence showing that the process of atherosclerosis already starts during adolescence [7]. There are also good reasons to believe that the anger-hostility constellation develops during childhood [8]. However, little is known about the etiological antecedents of this psychological risk factor. Several studies have evaluated the potential genetic basis for anger/hostility [9-12] and have come to the conclusion that there is a small to modest contribution of heritability to various aspects of anger and hostility. Other researchers have suggested that anger and hostility originate from family factors such as attachment style and parental rearing behaviors [8].

According to attachment theory, children develop an attachment style during the early stages of their life. More specifically, through interactions with primary caregivers, children will develop expectations about their caregiver's availability, which serve as the basis for internal working models of the self and the other. When experiences lead to the expectation that caregivers will be lovingly and responsive, children develop a secure attachment style; that is, they acquire a model of the self as loved and valued and a model of the other as warm and loving [13]. In contrast, when children have experiences that lead them to expect caregivers to be rejecting and unreliable, they are likely to develop an insecure attachment style. These children hold a model of the self as unloved and rejected and a model of the other as unloving and rejecting. It has been suggested that an insecure attachment style enhances the development of personality traits such as anger and hostility [14]. Although there is some evidence showing that insecurely attached children are more hostile and quick to anger than their securely attached counterparts [15], there is little direct support for a link between attachment status and the CHD risk factor of anger/hostility. One exception is a study by Meesters and Muris [16] who examined the connection between attachment style and individual differences in anger and hostility in a sample of female undergraduate students. Results demonstrated that insecurely attached young women reported higher levels of anger and hostility than their securely attached counterparts.

A limited number of studies have examined the role of parental rearing behaviors in the formation of anger/hostility. For example, Smith et al. [17] reported that highly hostile undergraduate students ascribed more conflict and less cohesion to their family of origin compared to their low hostile counterparts. In a related study by Houston and Vavak [18], young adults were asked to retrospectively describe their parents' behaviors. Results showed that high levels of hostility were associated with descriptions of parents displaying less acceptance, more harsh control, more interference in the person's desires as a child, and more punitiveness. Furthermore, Meesters et al. [19] investigated the relationship between perceived parental rearing behaviors and individual differences in hostility in a large sample of students. These authors found that high hostile subjects perceived more rejection and control and less emotional warmth of their parents than low hostile subjects. Similar results were obtained by Meesters and Muris [20] in a case-control study of middle-aged male myocardial infarction patients and healthy controls. That is, in both patients and controls, high levels of hostility were linked to high levels of rejection and low levels of emotional warmth.

Research on the link between parental rearing and anger/ hostility in child and adolescent samples has yielded highly comparable findings. Woodall and Matthews [21] reported that children who scored high on hostility and anger came from families that could be characterized as low on supportiveness and interpersonal involvement. These results were replicated in a further longitudinal study by these authors [22]. In that study, changes in and stability of hostility levels and their relationship to family support were examined among a sample of 10- to 18-year-old children and adolescents over a 4-year period. While results indicated that hostility levels remained relatively stable across the 4-year period, data also showed that declines in perceived family support were associated with greater temporal increase in hostile characteristics. Finally, Matthews et al. [23] tested whether a negative family environment led to the development of hostile traits in adolescent boys. Negative behaviors during a parent-son discussion aimed at resolving disagreements were observed in a laboratory setting. Boys' hostile traits were assessed at the time of the discussion and at a follow-up 3 years later. Results demonstrated that a high frequency of negative behaviors during the discussion task were predictive of boys' later hostile attitudes and expression of anger. Altogether, the results of these studies seem to justify the conclusion of Miller et al. [5] that hostile attitudes in youths partly seems to develop as a consequence of "parental behavior that (a) lacks genuine acceptance; (b) is overly strict, critical, and demanding of conformity; and (c) is inconsistent with regard to disciplinary treatment"' (p. 341). 
Muris, P., Meesters, C., Morren, M., Moorman, L.

Anger and hostility in adolescents: relationships with self-reported attachment

style and perceived parental rearing styles.

Journal of Psychosomatic Research: 57, 2004, nr. 3, p. 257-265

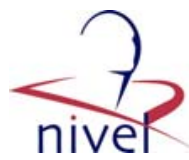

While there is evidence to support the notion that attachment style and parental rearing behaviors are involved in the development of anger/hostility, no study can be found that has examined the relative contribution of these family factors. The present study was set-up to examine this issue. A large group of adolescents $(N=441)$ completed (1) a simplified version of Hazan and Shaver's [24] single-item measure of attachment style; (2) the junior version of the "Egna Minnen Betra"ffende Uppfostran (EMBU)," which is Swedish for "my memories of upbringing," a questionnaire measuring perceptions of various aspects of parental rearing, namely, emotional warmth, rejection, control, and inconsistency [25]; (3) the Aggression Questionnaire (AQ), which assesses anger and hostility as well as behavioral aspects of aggression [26]; and (4) the trait anger subscale of the State- Trait Anger Scale (STAS) [27]. It was examined (a) whether adolescents who classify themselves as insecurely attached report higher levels of anger and hostility than adolescents who classify themselves as securely attached; (2) whether rejection, control, inconsistency, and lack of emotional warmth are accompanied by heightened levels of anger/ hostility; and (3) whether insecure attachment and parental rearing behaviors both account for a unique proportion in the variance of anger and hostility.

\section{METHOD}

\section{Participants and procedure}

Four hundred and forty-one adolescents (228 boys and 213 girls) of a regular secondary school ("Trevianum") in Sittard, The Netherlands, participated in the study after obtaining informed consent from their parents. Participation rate was very high (i.e., $>95 \%$ ). Mean age of the adolescents was 13.8 years (S.D. $=0.8$; range $12-16$ years). No exact information about the socioeconomic status of the adolescents was available. Adolescents either attended higher general secondary education $(39.9 \%)$ or preuniversity education $(60.1 \%)$, indicating above average to high intellectual functioning. The vast majority of the adolescents (more than $90 \%$ ) was Caucasian.

Participants completed the set of questionnaires anonymously in their classrooms. The teacher and a research assistant were always available to provide clarification if necessary and to ensure confidential and independent responding.

\section{Questionnaires}

An age-downward adaptation of Hazan and Shaver's [24] instrument for measuring attachment styles was used [28]. This measure is based on the assumption that attachment to a considerable extent defines intimate relationships. This implies that one can infer attachment status from children and adolescents' perceptions of close relationships. The instrument consists of three descriptions that correspond with three basic patterns of attachment: (1) "I find it easy to become close friends with other young people. I trust them and I am comfortable depending on them. I do not worry about being abandoned or about another child getting too close friends with me." (secure attachment); (2) "I am uncomfortable to be close friends with other young people. I find it difficult to trust them completely and difficult to depend on them. I get nervous when another child wants to become close friends with me. Friends often come more close to me than I want them to." (avoidant attachment); and (3) "I often find that other young people do not want to get as close as I would like them to be. I am often worried that my best friend doesn't really like me and wants to end our friendship. I prefer to do everything together with my best friend. However, this desire sometimes scares other young people away." (ambivalent attachment). Children and adolescents are asked to choose the description that applies best to them. A previous study by Muris et al. [29] has provided support for the validity of this instrument in a sample of young adolescents. That is, attachment style as determined by the singleitem measure was related to the quality of attachment to parents and peers as measured by the Inventory of Parent and Peer Attachment [30]. More precisely, adolescents who classified themselves as securely attached displayed higher levels of trust but lower levels of alienation than adolescents who classified themselves as insecurely (i.e., avoidantly or ambivalently) attached.

The junior version of the EMBU [25] originally consists of 41 items that can be allocated to four subscales: emotional warmth (14 items; e.g., "Your parents not only tell you that they love you, but they also hug and kiss you'), rejection (12 items; e.g., "Your parents wish that you were like somebody else"), overprotection (10 items; e.g., "Your parents want you to reveal your secrets to them'), and favoring subject (5 items; e.g., "Your parents favor you in relation to your brothers and 
Muris, P., Meesters, C., Morren, M., Moorman, L.

Anger and hostility in adolescents: relationships with self-reported attachment

style and perceived parental rearing styles.

Journal of Psychosomatic Research: 57, 2004, nr. 3, p. 257-265

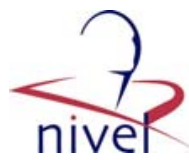

sisters'). In the present study, the questionnaire was changed in two ways. First, all items referring to brothers and sisters (i.e., the favoring subject subscale and two additional items) were removed because not all children had siblings. Second, five items were added in an attempt to cover parents' inconsistent rearing behaviors (e.g., "When I have done something wrong, it depends on the mood of my parents whether I am punished or not') as these are also thought to be linked to the development of hostility [5]. These items were taken from the Child Rearing Inventory [31]. As a result, the EMBU version that was used in the present study contained 39 items that had to be answered on a four-point Likert scale with $1=$ no, never, $2=y e s$, but seldom, $3=y e s$, often, and $4=y e s$, most of the time. For each EMBU item, children first assessed the father and then mother's rearing behavior. Previous research has indicated that the junior version of the EMBU is a reliable and valid questionnaire measuring children and adolescents' perceptions of parental rearing behaviors [25,32].

The AQ [26] is a 29-item self-report scale assessing the construct of aggression in three components: a behavioral component that is represented by the subscales of physical aggression (nine items; e.g., "If somebody hits me, I hit back") and verbal aggression (five items; e.g., "When people make me angry, I may tell them what I think of them"'), an emotional component that is covered by the subscale of anger (seven items; e.g., "I have trouble controlling my temper"), and a cognitive component that is represented by the subscale of hostility (eight items; e.g., "I wonder why sometimes I feel so bitter about things"'). Each item has to be answered on a five-point Likert scale anchored by $1=$ extremely unlike me and $5=$ extremely like me. Total aggression and subscale scores can be derived by summing across relevant items. Previous research has shown that the AQ has good psychometric properties [3336].

The trait anger subscale of the STAS [27] consists of 10 self-statements (e.g., "I am quickly annoyed"). Respondents indicate how they generally feel on a fourpoint scale with $1=$ almost never, $2=$ sometimes, $3=$ often, and $4=$ almost always. A total score can be computed by summing the ratings on all items. The STAS is a widely used instrument, which provides a reliable and valid index of trait anger [37].

\section{Statistical analysis}

The Statistical Package for Social Sciences (SPSS) was used for computing descriptive statistics, correlations, and carrying out $t$ tests, analyses of variance (ANOVAs), and stepwise regression analyses. In the regression analyses, insecure attachment (i.e., a dummy variable with $0=$ secure attachment and $1=$ avoidant and ambivalent attachment) and parental rearing behaviors were the predictor variables; whereas anger, hostility, and other aggression scores were the dependent variables. In this way, the relative contributions of both variables in predicting anger, hostility, and aggression were examined. As an aside, it should be mentioned that effects of gender were tested in all analyses. The results will only be presented in case there were diverging findings for boys and girls.

\section{RESULTS}

\section{General statistics}

Before addressing the main results of the current study, three remarks are in order. First, questionnaires were found to be reliable in terms of internal consistency. That is, most Cronbach's alphas were well above .60. However, there were a number of exceptions to this rule: the reliability of the AQ verbal aggression and the inconsistency scales of the EMBU were below acceptable limits (with $\alpha$ 's in the .45-.51 range). However, it should be noted that the itemtotal correlations for these scales were reasonable (i.e., between .14 and .36), and thus it seems likely that the low reliability coefficients were partly due to the fact that these scales only consisted of five items. Second, $t$ tests revealed a significant gender difference on the AQ physical aggression scale. More specifically, boys displayed higher levels of physical aggression than did girls $[t(439)=7.1, P<.001]$. Finally, correlations among AQ and STAS scores showed the predicted pattern. That is, all correlations were positive and significant (all $P$ 's $<.001$ ), with the most substantial correlation being that between AQ anger and STAS trait anger $(r=.67)$. 
Muris, P., Meesters, C., Morren, M., Moorman, L.

Anger and hostility in adolescents: relationships with self-reported attachment

style and perceived parental rearing styles.

Journal of Psychosomatic Research: 57, 2004, nr. 3, p. 257-265

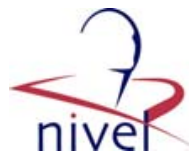

\section{Attachment style and anger, hostility, and aggression}

The number of adolescents who endorsed the secure, avoidant, and ambivalent attachment items was 405 (91.8\%; 214 boys and 191 girls), 11 (2.5\%; 4 boys and 7 girls), and 25 (5.7\%; 10 boys and 15 girls), respectively. Table 1 presents mean AQ and STAS scores of adolescents who defined themselves as either securely, avoidantly, or ambivalently attached. A series of ANOVAs with gender as a covariate revealed significant effects of attachment style for the AQ total score $[F(2,437)=6.2$, $P<.01]$, AQ anger $[F(2,437)=8.4, P<.001]$, AQ hostility $[F(2,437)=22.3, P<.001]$, and STAS trait anger $[F(2,437)=6.1, P<.01]$. Post hoc comparisons revealed that avoidantly and ambivalently attached adolescents displayed higher anger and hostility scores than securely attached adolescents. No significant differences in anger/hostility scores were found between avoidantly and ambivalently attached adolescents. Note further that attachment style did not have an effect on behavioral manifestations of aggression as indexed by the physical and verbal aggression subscales of the AQ.

\section{[ TABLE 1 ]}

\section{Parental rearing and anger, hostility, and aggression}

Partial correlations (corrected for gender) between parental rearing and indices of anger, hostility, and aggression are displayed in Table 2. As can be seen, data generally showed the predicted pattern. That is, negative correlations emerged between emotional warmth attributed to father and mother, on the one hand, and anger, hostility, and aggression scores, on the other hand. Furthermore, positive and in most cases significant relationships were found among rejection, control, and inconsistency of both parents and adolescents' scores of anger, hostility, and aggression. Altogether, these findings are in keeping with the notion that higher levels of negative rearing behaviors and lower levels of positive parental involvement are accompanied by higher levels of anger, hostility, and other types of aggression.

\section{[ TABLE 2 ]}

\section{Parental rearing, attachment status, and anger, hostility, and aggression}

The relationships between attachment style and parental rearing behaviors were examined with ANOVAs (with gender as a covariate). Results indicated that the three attachment style groups differed in terms of perceived parental rearing styles. Post hoc comparisons mainly demonstrated that insecurely attached adolescents deviated from securely attached adolescents. More precisely, avoidantly attached adolescents differed from securely attached adolescents in that they reported lower levels of emotional warmth (mother and father) and higher levels of rejection (mother and father) and inconsistency (father only). Further, ambivalently attached adolescents reported higher levels of rejection and control (father and mother) compared to their securely attached counterparts.

To examine whether parental rearing styles and attachment status accounted for a unique proportion of the variance in anger, hostility, and aggression scores, a series of stepwise regression analyses were carried out. The main results of these analyses are presented in Table 3. As can be seen, rejection of both parents appeared to be a significant predictor of anger, hostility, and aggression, accounting for a modest but significant proportion of the variance. Note also that inconsistency of the mother appeared to be a stable predictor, explaining a small but extra proportion of the variance in anger, hostility, and aggression scores. Insecure attachment entered in the regression equations predicting anger and hostility, indicating that this family factor only declared a unique proportion of emotional and cognitive components of aggression. Note that the contribution of the predictor variables was as hypothesized. That is, higher levels of rejection and inconsistency and an insecure attachment status were associated with higher levels of anger, hostility, and aggression. Finally, although the pattern of results was highly similar for boys and girls, it should be mentioned that in boys, predictor variables explained more variance in physical and verbal aggression $\left(R^{2}\right.$ change statistics varied between .13 and .18 in boys and between .06 and .07 in girls); whereas in girls, predictor variables accounted for a larger proportion of variance in anger and hostility $\left(R^{2}\right.$ change statistics varied between .15 and .33 in girls and between .13 and .22 in boys). 
Muris, P., Meesters, C., Morren, M., Moorman, L.

Anger and hostility in adolescents: relationships with self-reported attachment

style and perceived parental rearing styles.

Journal of Psychosomatic Research: 57, 2004, nr. 3, p. 257-265

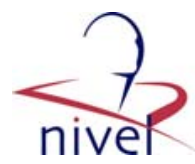

[ TABLE 3 ]

\section{DISCUSSION}

The present study examined the relationships between attachment and parental rearing and anger/hostility, which is widely recognized as a psychological risk factor for CHD [6], in a sample of nonclinical adolescents. The results can be catalogued as follows. First of all, attachment style appeared to be related to anger/hostility. More precisely, adolescents who defined themselves as avoidantly or ambivalently attached displayed higher levels of anger/hostility than adolescents who classified themselves as securely attached. Second, perceived parental rearing styles were found to be associated with anger/hostility. That is, low levels of emotional warmth and high levels of rejection, control, and inconsistency were accompanied by high levels of anger/hostility. Third and finally, both attachment status and parental rearing behaviors accounted for a unique and significant proportion of the variance in anger/hostility.

The current data demonstrate that both insecure attachment and negative parental rearing are linked to individual differences in anger/hostility. With regard to this finding, four additional remarks are in order. To begin with, although the results seem to be in line with the notion that these family factors are antecedents of anger/hostility $[5,14,18]$, it should be borne in mind that the present study employed a correlational approach, thereby making it impossible to draw conclusions on cause-effect or cyclic relationships. Thus, on the basis of the present data, one cannot conclude whether family factors precede anger/ hostility or vice versa or whether there are bidirectional links with negative family factors resulting in anger/hostility, which in turn further promote negative family factors, and so on. Second, the most clear-cut effects of insecure attachment were found for hostility. This may be due to the fact that hostility, as indexed by the AQ, refers to negative beliefs about and attitudes towards others, including cynicism, which refers to the belief that others are motivated by selfish concerns, and mistrust, which has to do with the expectation that others are likely to be provoking and harmful [38]. It is not unlikely that these hostility characteristics are cognitive derivatives of the distorted internal working models of avoidantly and ambivalently attached individuals. Third, insecure attachment was not linked to physical and verbal manifestations of aggression. This result comes close to that reported by Muris et al. [39] who found that insecure attachment did not account for unique variance when predicting symptoms of aggression and delinquency among youths. However, these authors noted that this finding may be due to fact that their study (just like the present investigation) relied on adolescents' self-report, which is probably a less favorable method for assessing symptoms of overt aggression [40]. Thus, it may well be the case that inclusion of parental and teacher data would have yielded significant associations between insecure attachment and physical/verbal aggression. Fourth, while previous research has indicated that anger/hostility can be considered as a risk factor for the development of physical illness, it is clear that high levels of this psychological construct may also indicate the presence of disruptive behavior disorders, such as oppositional defiant and conduct disorder [41].

Few gender differences were found in the present study. Boys scored higher on physical aggression than girls, a finding that is in keeping with previous research [26,35,42]. Most importantly, associations between attachment and parental rearing, on the one hand, and anger, hostility, and aggression, on the other hand, were highly comparable for boys and girls. The only remarkable gender difference was found in the results of the regression analyses, which showed that in boys predictor variables explained more variance in physical and verbal aggression, whereas in girls predictor variables accounted for a larger proportion of variance in anger and hostility. This finding may be the result of boys being more communicative about overt components of aggression, whereas girls may have a greater tendency of disclosing the more covert emotional and cognitive aspects [43].

Besides the aforementioned limitations regarding the correlational set-up of the study and its sole reliance on adolescents' self-report, a number of further shortcomings should be acknowledged. First, the study did not assess adolescents' medical condition. The inclusion of such data could certainly have strengthened this study and would have made it possible to test a model in which adverse family factors lead to high levels of anger/hostility, which in turn result in CHD-related physical problems. Second, the percentage of insecurely attached individuals was rather small. That is, less than $10 \%$ of the adolescents defined themselves as avoidantly or ambivalently attached, a figure that is remarkably 
Muris, P., Meesters, C., Morren, M., Moorman, L.

Anger and hostility in adolescents: relationships with self-reported attachment

style and perceived parental rearing styles.

Journal of Psychosomatic Research: 57, 2004, nr. 3, p. 257-265

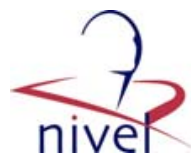

lower than the percentages reported elsewhere in the literature $[44,45]$. It seems most plausible that this aberrant finding has to do with the use of the one-item attachment style measure in youths. Previous studies employing this index have yielded similar low percentages of insecurely attached individuals in samples of children and adolescents [28,39]. It may well be the case that children and adolescents have a greater tendency to endorse the positively toned secure attachment item rather than the more negative descriptions of avoidant and ambivalent attachment. Third, the current study focused on attachment style and general parental rearing behaviors. It is clear that more specific parental behaviors such as the modeling of various types of aggression may also play an important role in the formation of aggression-linked traits. Fourth and finally, while the AQ and the STAS are wellrespected, reliable, and valid measures of anger/hostility in adults, it should be borne in mind that few studies have established their psychometric properties in children and adolescents [8]. Although the scales appeared reliable in terms of internal consistency and correlated in a theoretically meaningful way, further studies on the validity of these indices in youths are certainly needed.

There is increasing evidence indicating that physiological risk factors for CHD such as high lipid levels and elevated blood pressure are already evident in children and adolescents, and a substantial proportion of the youths maintain these elevated levels into adulthood. In addition, behavioral risk factors such as smoking and physical inactivity are often well established prior to young adulthood [8]. Future studies should further examine how anger/hostility interacts with these physiological and behavioral antecedents in the early pathogenesis of CHD [6]. When this research indeed demonstrates that anger/hostility promotes these risk factors for CHD, it may be worthwhile to develop prevention and intervention programs targeting at the elimination of this psychological risk factor in youths.

\section{ACKNOWLEDGMENT}

Teachers, staff, and children of the Trevianum College in Sittard, The Netherlands, are thanked for their participation in the present study.

\section{REFERENCES}

[1] Sirois BC, Burg MM. Negative emotion and coronary heart disease: a review. Behav Modif 2003;27:83- 102.

[2] Spielberger CD, Johnson EH, Russell SF, Crane RJ, Jacobs GA, Worden TJ. The experience and expression of anger: construction and validation of an anger expression scale. In: Chesney MA, Rosenman $\mathrm{RH}$, editors. Anger and hostility in cardiovascular and behavioral disorders. Washington: Hemisphere, 1985. pp. $5-30$.

[3] Matthews KA. Coronary heart disease and type A behaviors: update on and alternative to the Booth-Kewley and Friedman (1987) quantitative review. Psychol Bull 1988;104:373- 80.

[4] Miller TQ, Turner CW, Tindale RS, Posavac EJ, Dugoni BL. Reasons for the trend toward null findings in research on type A behavior. Psychol Bull 1991;110:469- 85.

[5] Miller TQ, Smith TW, Turner CW, Guijarro ML, Hallet AJ. A metaanalytic review of research on hostility and physical health. Psychol Bull 1996;119:322-48.

[6] Smith TW, Ruiz JM. Psychosocial influences on the development and course of coronary heart disease: current status and implications for research and practice. J Consult Clin Psychol 2002;70:548- 68.

[7] Matthews KA, Woodall KL. Childhood origins of overt type A behaviors and cardiovascular reactivity to behavioral stressors. Ann Behav Med 1988;10:71-7.

[8] Grunbaum JA, Vernon SW, Clasen CM. The association between anger and hostility and risk factors for coronary heart disease in children and adolescents: a review. Ann Behav Med 1997;19:179- 89.

[9] Carmelli D, Rosenman RH, Swan GE. The Cook and Medley Ho Scale: a heritability analysis in adult male twins. Psychosom Med 1988;50:165- 74.

[10] Cates DS, Houston BK, Vavak CR, Crawford MH, Uttley M. Heritability of hostility-related emotions, attitudes, and behaviors. J Behav Med 1993;16:237- 56.

[11] Pedersen NL, Lichtenstein P, Plomin R, DeFaire U, McClearn GE, Matthews KA. Genetic and environmental influences for type A-like measures and related traits: a study of twins reared apart and twins reared together. Psychosom Med 1989;51:428-40.

[12] Smith TW, McGonigle M, Turner CW, Ford MH, Slattery ML. Cynical hostility in adult male twins. Psychosom Med 1991;53:684- 92. 
Muris, P., Meesters, C., Morren, M., Moorman, L.

Anger and hostility in adolescents: relationships with self-reported attachment style and perceived parental rearing styles.

Journal of Psychosomatic Research: 57, 2004, nr. 3, p. 257-265

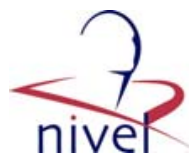

[13] Bretherton I. Attachment theory. Retrospect and prospect. In: Bretherton I, Waters E, editors. Growing points of attachment theory and research. Monogr Soc Res Child Dev 1985;50:3- 35.

[14] Thoresen CE, Pattillo JR. Exploring the type A behavior pattern in children and adolescents. In: Houston BK, Snyder CR, editors. Type A behavior pattern: research, theory, and intervention. New York: Wiley, 1988. pp. 98- 145.

[15] Main M, Kaplan N, Cassidy J. Security in infancy, childhood, and adulthood: a move to the level of representation. In: Bretherton I, Waters E, editors. Growing points of attachment theory and research. Monogr Soc Res Child Dev 1985;50:66 - 104.

[16] Meesters C, Muris P. Attachment style and self-reported aggression. Psychol Rep 2002;90:2315 .

[17] Smith TW, Pope MK, Sanders JD, Allred KD, O'Keeffe JL. Cynical hostility at home and work: psychosocial vulnerability across domains. J Res Pers 1988;22:525- 48.

[18] Houston BK, Vavak CR. Cynical hostility: developmental factors, psychosocial correlates, and health behaviors. Health Psychol 1991; 10:9-17.

[19] Meesters C, Muris P, Esselink T. Hostility and perceived parental rearing behaviour. Pers Individ Differ 1995;18:567-70.

[20] Meesters C, Muris P. The relationship between hostility and perceived parental rearing behavior: a study of male myocardial infarction patients and healthy controls. Pers Individ Differ 1996;21:27181.

[21] Woodall KL, Matthews KA. Familial environment associated with type A behaviors and psychophysiological responses to stress in children. Health Psychol 1989;8:403-26.

[22] Woodall KL, Matthews KA. Changes in and stability of hostile characteristics: results from a 4year longitudinal study of children. J Pers Soc Psychol 1993;64:491-9.

[23] Matthews KA, Woodall KL, Kenyon K, Jacob T. Negative family environment as a predictor of boys' future status on measures of hostility attitudes, interview behavior, and anger expression. Health Psychol 1996;15:30 - 7 .

[24] Hazan C, Shaver P. Romantic love conceptualized as an attachment process. J Pers Soc Psychol $1987 ; 52: 511-24$.

[25] Castro J, Toro J, Van der Ende J, Arrindell WA. Exploring the feasibility of assessing perceived parental rearing styles in Spanish children with the EMBU. Int J Soc Psychiatry 1993;39:47-57.

[26] Buss AH, Perry M. The Aggression Questionnaire. J Pers Soc Psychol 1992;63:452-9.

[27] Spielberger CD, Jacobs GA, Russell SF, Crane RJ. Assessment of anger: the State-Trait Anger Scale. In: Butcher JN, Spielberger CD, editors. Advances in personality assessment. vol 2. Hillsdale (NJ): Lea \& Febiger, 1983. pp. 159- 87.

[28] Muris P, Mayer B, Meesters C. Self-reported attachment style, anxiety, and depression in children. Soc Behav Pers 2000;28:157-62.

[29] Muris P, Meesters C, Van Melick M, Zwambag L. Self-reported attachment style, attachment quality, and symptoms of anxiety and depression in young adolescents. Pers Individ Differ 2001;30:809-18.

[30] Armsden GC, Greenberg MT. The Inventory of Parent and Peer Attachment: individual differences and their relationship to psychological well-being in adolescence. J Youth Adolesc 1987;16:427-54.

[31] Krohne HW, Kiehl GE, Neuser KW, Pulsack A. Das "Erziehungsstil- Inventar" (ESI): konstruktion, psychometrische Kenwerte, Gu" Itigkeitsstudien [The Child Rearing Style Inventory (ESI): construction, psychometric properties, validity studies]. Diagnostica 1984;30: 299-318.

[32] Muris P, Bosma H, Meesters C, Schouten E. Perceived parental rearing behaviours: a confirmatory factor analytic study of the Dutch EMBU for children. Pers Individ Differ 1998;24:43942.

[33] Archer J, Kilpatrick G, Bramwell R. Comparison of two aggression questionnaires. Aggress Behav 1995;21:371- 80.

[34] Harris JA. Confirmatory factor analysis of the Aggression Questionnaire. Behav Res Ther 1995;33:991- 3.

[35] Meesters C, Muris P, Bosma H, Schouten E, Beuving S. Psychometric evaluation of the Dutch version of the Aggression Questionnaire. Behav Res Ther 1996;34:839- 43.

[36] Morren M, Meesters C. Validation of the Dutch version of the Aggression Questionnaire in adolescent male offenders. Aggress Behav 2002;28:87 - 96.

[37] Deffenbacher JL, Oetting ER, Thwaites GA, Lynch RS, Baker DA, Stark DA, Thacker S, EiswerthCox L. State-trait anger theory and the utility of the Trait Anger Scale. J Couns Psychol 1996;43: $131-48$. 
Muris, P., Meesters, C., Morren, M., Moorman, L.

Anger and hostility in adolescents: relationships with self-reported attachment style and perceived parental rearing styles.

Journal of Psychosomatic Research: 57, 2004, nr. 3, p. 257-265

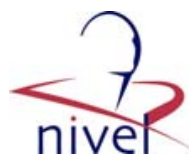

[38] Smith TW. Concepts and methods in the study of anger, hostility, and health. In: Siegman AW, Smith TW, editors. Anger, hostility, and the heart. Hillsdale (NJ): Erlbaum, 1994. pp. 23- 42.

[39] Muris P, Meesters C, Van den Berg S. Internalizing and externalizing problems as correlates of self-reported attachment style and perceived parental rearing in normal adolescents. J Child Fam Stud 2003;12: 171- 83.

[40] Achenbach TM, McConaughy SH, Howell CT. Child/adolescent behavioral and emotional problems: implications of cross-informant correlations for situational specificity. Psychol Bull 1987;101: 213-32.

[41] American Psychiatric Association. Diagnostic and Statistical Manual of Mental Disorders, fourth edition-text revision (DSM-IV-TR). Washington (DC): American Psychiatric Association, 2000.

[42] Harris MB. Aggressive experiences and aggressiveness: relationships to ethnicity, gender, and age. J Appl Soc Psychol 1996;26: 843- 70.

[43] Boldizar JP. Assessing sex typing and androgyny in children: the children's sex role inventory. Dev Psychol 1991;27:505-15.

[44] Crowell JA, Fraley RC, Shaver PR. Measurement of individual differences in adolescent and adult attachment. In: Cassidy J, Shaver PR, editors. Handbook of attachment: theory, research, and clinical applications. New York: Guilford Press, 1999. pp. 434- 65.

[45] Solomon J, George C. The measurement of attachment security in infancy and childhood. In: Cassidy J, Shaver PR, editors. Handbook of attachment: theory, research, and clinical applications. New York: Guilford Press, 1999. pp. 287-316.

\section{TABLES AND FIGURES}

Table 1

Mean anger, hostility, and aggression scores of adolescents who classified themselves as securely, avoidantly, or ambivalently attached

\begin{tabular}{|c|c|c|c|c|c|}
\hline & \multicolumn{5}{|c|}{ Attachment style } \\
\hline & $\begin{array}{l}\text { Secure } \\
(n=405)\end{array}$ & $\begin{array}{l}\text { Avoidant } \\
(n=11)\end{array}$ & $\begin{array}{l}\text { Ambivalent } \\
(n=25)\end{array}$ & $F^{*}$ & $P$ \\
\hline \multicolumn{6}{|l|}{$\overline{\mathrm{AQ}}$} \\
\hline Total score & $74.9(15.4)^{\mathrm{a}}$ & $85.1(15.6)^{\mathrm{b}}$ & $83.1(13.2)^{\mathrm{b}}$ & 6.0 & $<.01$ \\
\hline $\begin{array}{l}\text { Physical } \\
\text { aggression }\end{array}$ & $24.7(7.1)$ & $24.5(5.1)$ & $23.0(6.2)$ & 0.4 & ns \\
\hline $\begin{array}{l}\text { Verbal } \\
\text { aggression }\end{array}$ & $13.7(2.8)$ & $14.0(4.2)$ & $14.2(3.1)$ & 0.4 & $\mathrm{~ns}$ \\
\hline Anger & $16.6(4.7)^{\mathrm{a}}$ & $21.6(5.9)^{\mathrm{b}}$ & $19.1(5.0)^{\mathrm{b}}$ & 8.4 & $<.001$ \\
\hline Hostility & $19.9(5.5)^{\mathrm{a}}$ & $24.9(5.1)^{\mathrm{b}}$ & $26.8(4.2)^{\mathrm{b}}$ & 22.3 & $<.001$ \\
\hline \multicolumn{6}{|l|}{ STAS } \\
\hline Trait anger & $17.4(4.3)^{\mathrm{a}}$ & $20.4(3.8)^{\mathrm{b}}$ & $19.8(4.6)^{\mathrm{b}}$ & 6.1 & $<.01$ \\
\hline
\end{tabular}

Means that do not share the same superscripts differ at $P<.05$ (post hoc comparisons); ns= nonsignificant.

* As obtained with ANOVAs with gender as a covariate.
Table 3

Main results of stepwise regression analyses with EMBU scales and attachment status being predictors and anger, hostility, and aggression scores being the dependent variables ${ }^{a}$

\begin{tabular}{lllll}
\hline Dependent & \multicolumn{1}{l}{ Predictors } & Partial $r$ & $P$ & $R^{2}$ change \\
\hline EMBU scales-Mother and insecure attachment & & & \\
AQ & & & & \\
Total score & 1. Rejection & .48 & $<.001$ & .23 \\
& 2. Inconsistency & .20 & $<.001$ & .03 \\
Physical & 1. Rejection & .29 & $<.001$ & .07 \\
$\quad$ aggression & 2. Inconsistency & .13 & $<.01$ & .01 \\
Verbal & 1. Rejection & .37 & $<.001$ & .14 \\
$\quad$ aggression & 2. Inconsistency & .17 & $<.001$ & .02 \\
Anger & 1. Rejection & .39 & $<.001$ & .15 \\
& 2. Inconsistency & .12 & $<.05$ & .01 \\
\multirow{4}{*}{ Hostility } & 3. Insecure attachment & .11 & $<.05$ & .01 \\
& 1. Rejection & .44 & $<.001$ & .20 \\
& 2. Insecure attachment & .24 & $<.001$ & .04 \\
& 3. Inconsistency & .18 & $<.001$ & .03 \\
STAS & 4. Control & .15 & $<.01$ & .02 \\
Trait anger & 1. Rejection & .43 & $<.001$ & .18 \\
& 2. Inconsistency & .20 & $<.001$ & .03
\end{tabular}

\begin{tabular}{lllll} 
EMBU scales-Father and insecure attachment & & \\
AQ & & & \\
Total score & 1. Rejection & .46 & $<.001$ & .21 \\
& 2. Control & .13 & $<.01$ & .01 \\
3. Inconsistency & .12 & $<.05$ & .01 \\
Physical & 1. Rejection & .30 & $<.001$ & .08 \\
$\quad$ aggression & & & & \\
Verbal & 1. Rejection & .35 & $<.001$ & .12 \\
$\quad$ aggression & & & & \\
Anger & 1. Rejection & .37 & $<.001$ & .14 \\
2. Insecure attachment & .11 & $<.05$ & .01 \\
Hostility & 1. Rejection & .41 & $<.001$ & .17 \\
& 2. Control & .26 & $<.001$ & .05 \\
3. Insecure attachment & .22 & $<.001$ & .04 \\
STAS & 1. Rejection & .39 & $<.001$ & .15 \\
Trait anger & 2. Inconsistency & .13 & $<.01$ & .01 \\
\hline
\end{tabular}

${ }^{a}$ Numbers refer to the step on which the predictor variable was entered in the regression equation; only significant predictors are shown. To control for gender, this variable was forced in the equation on Step 0 . 
Muris, P., Meesters, C., Morren, M., Moorman, L.

Anger and hostility in adolescents: relationships with self-reported attachment style and perceived parental rearing styles.

Journal of Psychosomatic Research: 57, 2004, nr. 3, p. 257-265



Table 2

Partial correlations (corrected for gender) between parental rearing and anger, hostility, and aggression scores $(N=441)$

\begin{tabular}{|c|c|c|c|c|c|c|}
\hline & \multicolumn{5}{|l|}{ AQ } & \multirow{2}{*}{$\begin{array}{l}\text { STAS } \\
\text { Trait anger }\end{array}$} \\
\hline & $\begin{array}{l}\text { Total } \\
\text { score }\end{array}$ & $\begin{array}{l}\text { Physical } \\
\text { aggression }\end{array}$ & $\begin{array}{l}\text { Verbal } \\
\text { aggression }\end{array}$ & Anger & Hostility & \\
\hline \multicolumn{7}{|l|}{ EMBU_-Mother } \\
\hline Emotional warmth & $-.21 * *$ & $-.13^{*}$ & $-.11^{*}$ & $-.21 * *$ & $-.18^{* *}$ & $-.14 *$ \\
\hline Rejection & $.48^{* * *}$ & $.29 * *$ & $.37^{*} *$ & $.39 * *$ & $.44^{* * *}$ & $.43^{* *}$ \\
\hline Control & $.26^{* * *}$ & .07 & $.22 * *$ & $.21 * *$ & $.33^{* *}$ & $.26 * *$ \\
\hline Inconsistency & $.41^{* *}$ & $.26^{* * *}$ & $.33^{* * *}$ & $.31 * *$ & $.37 * *$ & $.39 * *$ \\
\hline \multicolumn{7}{|l|}{ EMBU-Father } \\
\hline Emotional warmth & $-.19 * *$ & $-.15^{*}$ & $-.10^{*}$ & $-.21 * *$ & $-.13^{*}$ & $-.14 *$ \\
\hline Rejection & $.46^{* *}$ & $.30^{* * *}$ & $.35^{* *}$ & $.37 * *$ & $.41^{* *}$ & $.39 * *$ \\
\hline Control & $.24 * *$ & .06 & $.17 * *$ & $.20 * *$ & $.34 * *$ & $.19^{* * *}$ \\
\hline Inconsistency & $.35^{* *}$ & $.22 * *$ & $.26^{* *}$ & $.28 * *$ & $.32 * *$ & $.31 * *$ \\
\hline
\end{tabular}

* $P<05$

** $P<.001$ 